Persp. Teol. 41 (2009) 233-252

\title{
O hUMANISMO PERSONALISTA DE LIMA VAZ: UMA RESPOSTA FILOSÓFICA AO PROBLEMA DO ABORTO
}

\author{
(The personalistic humanism of Lima Vaz: A philosophic response to the \\ problem of abortion)
}

\author{
Eleandro Teles *
}

RESUMO: Uma posição contrária ou favorável ao aborto depende da resposta à questão bioética elementar: quando tem início a vida qualitativamente humana no feto? Adotando o princípio da inviolabilidade da vida humana como critério ético fundamental de análise, busca-se responder à pergunta sobre o status do embrião a partir da antropologia personalista de Lima Vaz. Conforme o autor, a pessoa humana é compreendida na tríplice estrutura: somática, psíquica e espiritual. Uma nova e ampla categoria de pessoa é proposta: ser humano, unidade de estrutura e relações, convocada a realizar-se pelo movimento dialético de expressão do dado somático, através das relações fundamentais com o mundo, o outro e o Absoluto, abrangendo toda a existência, desde a fecundação até a morte. $\mathrm{O}$ humanismo personalista de Lima Vaz oferece uma resposta filosófica contundente ao problema do aborto.

PALAVRAS-CHAVE: Aborto, Vida humana, Pessoa, Estrutura, Relação.

ABSTRACT: A stand against or in favor of abortion depends on the answer to the elementary bioethical question: when is the beginning of the human life in a fetus? Adopting the principle of inviolability of human life as the fundamental ethical criterion of analysis and using Lima Vaz's personalistic anthropology, we search for an answer to the question about the embryo status. According to the author, the human person is comprehended in the triple structure: somatic, psychic and spiritual. A new and broad category of person is proposed: the human being, unity

* Departamento de Filosofia da Universidade de Caxias do Sul. Artigo submetido a avaliação no dia 12/09/2008 e aprovado para publicação no dia 18/11/2008. 
of structure and relations, is called to self realization by the dialectical movement of expression from the somatic base, through the fundamental relations with the world, the other and the Absolute, including the entire existence, from fecundation until death. Lima Vaz's personalistic humanism offers a forceful philosophical answer to the problem of abortion.

KEY-WORDS: Abortion, Human life, Person, Structure, Relation.

\section{Aborto, ciência e filosofia}

$\mathrm{O}$ núcleo do atual debate público sobre o problema da legalização do aborto no Brasil consiste na tensão moral entre os princípios, supostamente antagônicos, da liberdade da mulher e da inviolabilidade da vida humana. Uma posição contrária ou favorável à prática do abortamento só pode ser adotada a partir da reflexão filosófica sobre esses argumentos. Se a vida da pessoa humana for compreendida como sendo "sagrada", não no sentido religioso do termo, mas sob um paradigma ético-moral, isto é, portadora de um valor absoluto, fim em si mesma, portanto inviolável, então, a pergunta que se faz necessária é: “quando ela começa?”. Quando tem início a vida qualitativamente humana num embrião? Os que respondem a essa questão afirmando que a concepção é o momento inicial da vida humana veem o aborto como um ato abominável, um crime contra o ser humano no seu estado vital mais frágil e indefeso. Outros argumentam que nas primeiras fases da gestação não se pode pensar em vida qualitativamente humana, menos ainda em termos de "pessoalidade": o feto não é ser humano, não é gente, não é pessoa, não tem direito algum à vida.

Para muito além do mero aspecto da legalidade, ou do ponto de vista religioso, o conflito central da questão bioética sobre o aborto reside no âmbito da moralidade dessa ação. $\mathrm{O}$ fato de a prática abortiva ser legalizada em diversos países, sobretudo naqueles chamados "desenvolvidos", não significa que se tenha resolvido ou chegado a um ponto pacífico sobre o problema ético, que constitui o centro da polêmica. A legalização do aborto por parte do Estado não redime nem altera de forma alguma o caráter intrinsecamente mau da ação. $\mathrm{O}$ caráter legal de uma ação jamais é critério válido para definir seu caráter moral e ético; o que deve ocorrer é justamente o contrário. Porque a verdade ética e moral não pode ser simplesmente "criada" por uma corte judicial, por mais suprema que seja sua instância. O juízo ético-moral é que deve definir a legalidade ou não de um ato perante uma sociedade que se pretenda "civilizada", "humanista" ou "desenvolvida". Ora, o discurso sobre os problemas existenciais e o sentido das ações humanas no mundo não pode ser deixado à mercê de veredictos reducionistas e simplistas do direito positivo, por mais legítima e basilar que seja a instituição jurídica em uma democracia consolidada. 
Nem tampouco pode-se depender exclusivamente de certos prognósticos mecanicistas das ciências biomédicas, que, embora todas elas aplicando métodos "científicos", são incapazes de chegar a um consenso "científico" sobre o momento inicial da vida qualitativamente humana do feto. Antes, porém, todo o discurso sobre ética e moral é de caráter filosófico. A questão do aborto, na qual está implicado diretamente o problema do momento inicial da vida humana, é, portanto, de cunho fundamentalmente filosófico. Trata-se de uma reflexão que pertence, não exclusivamente, mas primordialmente à antropologia filosófica.

As profundas transformações tecnológicas, a partir da metade do século $\mathrm{XX}$, as grandes descobertas científicas e, especialmente, o espantoso desenvolvimento das ciências biológicas "colocam questões novas e cruciais sobre a estrutura radical e comportamental do ser humano. São dúvidas que emergem diretamente da tecnociência, mas que ela não é capaz de responder porque já não são mais questões técnicas mas éticas"11. A pergunta antropológico-filosófica pelo momento inicial da vida humana pode ser formulada de inúmeras maneiras, sem que se perca seu questionamento fundamental: "o feto é uma pessoa?"; "existe vida qualitativamente humana a partir da fecundação, ou o embrião é apenas um ser humano em potencial?"; "quando se fala de aborto, entende-se o ser que está sendo gerado no útero materno como pessoa e, portanto, com vida e direitos próprios invioláveis, ou como um conglomerado de células à mercê da vontade e deliberação da proprietária do corpo?"; "é possível, de fato, delinear seguramente, ou cientificamente, o momento exato em que o 'produto da fecundação' passa a ter qualidade de ser humano?"; "a partir de quando, de que semana, de que dia, de que hora, de que minuto, um feto pode ser considerado pessoa humana?". "A identidade 'humana' do embrião constitui a argumentação basilar da fundamentação do direito à vida. [...] Todas as outras giram à volta desta"2.

Os dados atuais das ciências biomédicas sobre o desenvolvimento embrionário não apresentam um momento preciso que seja aceito consensualmente entre os cientistas como o marco inicial de uma vida propriamente humana. Todavia, a escola genética, em contraposição à desenvolvimentista, já há muito define o produto da fecundação como algo vivo; biologicamente diferente do útero materno; uma combinação dos cromossomos maternos e paternos, mas com patrimônio genético (DNA) novo; uma vida biologicamente humana e individual, pois possuidora de

${ }^{1}$ O.A. PEGORARO, Ética e bioética: Da subsistência à existência, Petrópolis: Vozes, 2002 , p. 22.

${ }^{2}$ S. LEONE / S. PRIVITERA / J.T. da CUNHA (orgs.), "Interrupção voluntária da gravidez", in Dicionário de Bioética, Vila Nova de Gaia / Aparecida: Perpétuo Socorro / Santuário, 2004, p. 601. 
patrimônio genético próprio e exclusivo, derivado da combinação dos 23 pares cromossômicos da espécie humana ${ }^{3}$. A embriologia esclarece que a formação do ser humano é um processo continuado, onde são constatados diferentes estágios de desenvolvimento, os quais seguem unicamente aquele processo genético fixado no momento da fecundação do óvulo pelo espermatozoide. Portanto, é a partir da fecundação que inicia-se o processo gerativo da vida humana.

Embora os dados da genética não deixem dúvidas, alguns cientistas insistem em contestar a fecundação do óvulo como marco inicial da vida qualitativamente humana. O certo é que a ciência, por si só, não dá conta de oferecer uma posição consensual sobre o momento do "big-bang" da vida humana. Ela pode, e é isto que ela faz, oferecer dados cada vez mais valiosos acerca do desenvolvimento de um ser humano, desde a concepção, passando pelo nascimento e ao longo de toda a vida. Mas esse cabedal de tecnologias e informações de que dispomos, através de avançadas pesquisas, tenderá sempre a fracassar se a pretensão for a de precisar "cientificamente" o tempo em que o feto em gestação pode ou deve ser considerado um "ser humano". Essa problemática, do sentido de ser ou não humano e de ser ou não pessoa, é uma questão fundamentalmente filosófica, e não científica ${ }^{4}$. Por mais contributos que a ciência possa oferecer, a tarefa de pensar e refletir sobre o ser humano continuará sempre uma tarefa eminentemente filosófica. Para muito além de certas pretensões de um neocientificismo, o sentido da vida da pessoa humana não se compreende no horizonte de um microscópio. Por mais avançados que possam ser os instrumentos técnicos ou meios experimentais de que disponham as ciências biomédicas, a "vida humana" jamais será passível de dissecação numa mesa de laboratório, ainda que sua estrutura somática o seja. A "vida humana" permanecerá sempre uma pergunta, uma pergunta filosófica.

O "credo" do cientificismo moderno dogmatizava, desde os "púlpitos" iluministas e positivistas, o grande triunfo das capacidades ilimitadas da racionalidade científica, a ponto de decodificar o ser humano em todos os sentidos possíveis, reduzindo-o a mais um objeto de estudo ou "análise". Entretanto, a primeira década do século XXI findar-se-á, ao que tudo indica, com pelo menos uma certeza científica: a vida do homem permanece um mistério para ele próprio. À sombra da velha trave do Oráculo de Delfos, "Conhece-te a ti mesmo", o perguntar pelas razões que fundam o

\footnotetext{
${ }^{3}$ Cf. F. COMPAGNONI / G. PIANA / S. PRIVITERA (orgs.), "Interrupção da gravidez", in Dicionário de Teologia Moral, São Paulo: Paulus, 1997, p. 638.

${ }^{4}$ Cf. A.C. VARGA, Problemas de Bioética, São Leopoldo: Unisinos, 1990, p. 68.

${ }^{5}$ Cf. L.C. BOMBASSARO / J. PAVIANI, As fontes do humanismo latino, Porto Alegre: EDIPUCRS, 2004, v. 3, p. 17.
} 
humano permanece uma questão eminentemente filosófica ${ }^{5}$. É tarefa da filosofia esclarecer os conceitos e oferecer caminhos racionais para a compreensão do sentido do existir humano, bem como elucidar o discurso acerca dos grandes problemas morais e existenciais da vida do homem - como o caso do aborto e a pergunta pelo momento inicial da vida no feto - frente aos quais, somente os dados das ciências não bastam para que se chegue a uma resposta satisfatória.

\section{A antropologia filosófica contemporânea}

A antropologia filosófica contemporânea compreende o homem como um "ser de relações", um ser "biorrelacional", constituído a partir dos dados físico-biológicos e das relações intersubjetivas que estabelece ao longo de toda a vida, do nascimento até a morte. Nesse sentido, também o conceito de vínculo elucida o significado de uma vida humanizada ${ }^{6}$. Aplicando-se essa análise à vida intrauterina - num horizonte ético acerca da problemática do aborto -, toda a força dos conceitos "homem" e "humano" não pode, portanto, ficar reduzida ao simples dado biológico, na pretensão de calcular o momento exato do desenvolvimento embrionário em que se possa definir o início da vida da persona ${ }^{7}$. Isso constituiria o aprisionamento do ser humano na "[...] mera dimensão biológica, esquecendo a riqueza de suas muitas outras facetas. Ora, cabe justamente à bioética a função de recordar estas 'outras' facetas, uma vez que, em primeiro lugar, ela é uma visão filosófica (não científica) [...]"8 do homem e de sua humanidade.

“O pluralismo antropológico atual se reflete, naturalmente, sobre as orientações éticas" ${ }^{\prime \prime}$. A reflexão antropológica contemporânea apresenta alguns "modelos de antropologia filosófica", ou modelos de "imagens do homem" na perspectiva da filosofia. Dentre tais concepções, que buscam responder à pergunta ontológica fundamental "o que é o homem?", destacam-se as antropologias existencial, materialista e personalista ${ }^{10}$.

Não obstante a importância e permanência da ideia de universalidade e

\footnotetext{
${ }^{6}$ Cf. L. PESSINI / Ch. de P. de BARCHIFONTAINE, Problemas atuais de bioética, $6^{\mathbf{a}}$ ed., São Paulo: São Camilo / Loyola, 2002, p. 230.

7 "A máscara mostra o personagem que é representado: um rei, um palhaço, uma donade-casa, um empregado. Portanto, a persona, 'máscara', oculta o ator e ao mesmo tempo 're-vela' o personagem: ela vela e desvela ao mesmo tempo. Esta imagem terá enorme importância na fenomenologia heideggeriana, a respeito da hermenêutica da 'existência que nós sempre somos' (Heidegger, 1998: 33)” (PEGORARO, Ética e bioética, p. 54).

${ }^{8}$ PEGORARO, Ética e bioética, p. 18.

${ }^{9}$ S. SPINSANTI, Ética biomédica, São Paulo: Paulinas, 1990, p. 72.

${ }^{10}$ Cf. H.Cl. de LIMA VAZ, Antropologia filosófica, $7^{\text {a }}$ ed., São Paulo: Loyola, 2004, v. 1, pp. 128-135.
} 
centralidade da pessoa humana em sua relação com a natureza, herança de vinte e cinco séculos de tradição filosófica, a atual reflexão antropológica busca

[...] reconhecer a pluridimensionalidade dos sentidos que a experiência de seu próprio ser revela ao homem [...]. Nesse caso, não é a centralidade de um lugar único gerador de sentido (como o lógikon clássico ou o Cogito cartesiano), mas a pluralidade de lugares de sentido que permite igualmente a pluralidade dos discursos antropológicos ${ }^{11}$.

Frente à diversidade cultural e social dos Estados liberais contemporâneos, e a atual fragmentação da filosofia, da religião e da ética, a contribuição da antropologia filosófica à reflexão bioética contemporânea consiste em oferecer uma compreensão integral da pessoa humana, um paradigma que sirva como critério ético relevante num amplo diálogo sobre os grandes desafios morais da atualidade, entre eles o aborto.

Hoje, conforme Lima Vaz, a ideia de homem parece ter perdido definitivamente sua unidade. A tarefa de uma antropologia filosófica consistiria, pois, na recuperação desta ideia da unidade do ser humano. Esta é a missão à qual a antropologia personalista se propõe: recuperar a visão integral e unitária do sujeito pessoal ${ }^{12}$; explicitar e analisar a estrutura e formação humanas do homem, como condição e processo presentes desde a concepção até a morte.

\section{O humanismo personalista de Lima Vaz}

O modelo contemporâneo da antropologia personalista, conforme os escritos de Lima Vaz, pretende delinear um horizonte ético que oriente qualquer discussão acerca do sentido moral dos comportamentos humanos. Um modelo “[...] mais leve que o personalismo clássico"13, a atual reflexão antropológica personalista concebe, numa articulação dialética, a passagem do ser humano como dado à sua expressão, isto é, " [...] a elevação do dado biológico ao evento da pessoa"14. Esse movimento dialético de elevação do homem como ser natural à sua expressão acontece na relação com os outros. O sujeito, que reflete sobre suas relações, é o mediador desse processo. O homem é um ser, portanto, fundamentalmente relacional. É nesta relação com o mundo, com as pessoas e com o Absoluto que o ser humano vai construindo-se: realizando-se como pessoa ${ }^{15}$.

${ }^{11}$ Ibid., p. 136.

${ }^{12}$ Cf. ibid., pp. 141-142.

${ }^{13}$ PEGORARO, Ética e bioética, p. 93. Sobre o personalismo clássico, ver ibid., pp. 87-92.

${ }^{14}$ Ibid., p. 94.

${ }^{15} \mathrm{Cf}$. ibid. 
O atual modelo antropológico personalista retoma, de certa forma, os personalismos de inspiração cristã ${ }^{16}$. Tais personalismos referem-se, constantemente, à antropologia clássica, à tradição tomista e suas reelaborações, e às linhas antropológicas de fundo fenomenológico. Segundo Lima Vaz, a característica fundamental compartilhada por estas formas de personalismo é a "[...] afirmação do Deus pessoal transcendente como paradigma e fim último da pessoa"17.

No horizonte da antropologia filosófica personalista, a análise do nosso autor apresenta uma compreensão de homem a partir de três conceitos fundamentais ${ }^{18}$ : estrutura, relação e unidade. Pelo conceito de estrutura distingue-se: 1) a estrutura somática (categoria do corpo próprio); 2) a estrutura psíquica (categoria do psiquismo); e 3) estrutura espiritual (categoria do espírito). $\mathrm{O}$ conceito de relação compreende: 1) relação com o mundo (categoria da objetividade); 2) relação com o Outro (categoria de intersubjetividade); e 3) relação com o Absoluto (categoria de transcendência). Por fim, no conceito de unidade distingue-se: 1) unidade como unificação (categoria da realização); e 2) unidade como ser-uno (categoria da essência). Sob o conceito de unidade, o homem é compreendido como pessoa. "A pessoa aparece, assim, como ato total, que opera a síntese entre as categorias de estrutura e as categorias de relação por meio de seu desenvolvimento existencial, ou seja, de sua auto-realização"19.

A pessoa está sempre aberta à infinitude do sentido, como ser de natureza espiritual. Ela se realiza enquanto realiza o seu ser ontológico. Nessa perspectiva, jamais a definição de "pessoa" pode ser reduzida às qualidades do sujeito, ou às suas dimensões psíquicas, como consciência, interioridade, autonomia e liberdade. Da mesma forma, o fator físico-biológico, isto é, o corpo do indivíduo, não é o dado único ou mais importante quando se pensa sobre a "hominização do homem", antes, é através dele que "[...] o ser humano está no mundo e com os outros, isto é, o corpo é o palco pelo qual cada ser humano se abre ao mundo e ao outro" ${ }^{20}$.

\footnotetext{
16 "Entre os personalistas cristãos mais conhecidos, podemos enumerar Jacques Maritain (1882-1973), cuja estrita fidelidade ao tomismo não o impediu de formular uma concepção de pessoa largamente aberta aos grandes problemas da civilização contemporânea; Emmanuel Mounier (1905-1950), que ligou o nome do personalismo a um movimento político-cultural por ele fundado e teve uma presença notável na vida católica dos anos 30 a 60; Maurice Nédoncelle (1905-1976), cuja notável obra filosófica é orientada para a fundamentação de um personalismo cristão que acolhe importantes contribuições da análise fenomenológica; Joseph de Finance (1904), cujas notáveis contribuições no domínio da ética de inspiração tomista inserem-se numa rigorosa e amplamente arquitetada filosofia da pessoa. Entre os personalistas cristãos de língua alemã, convém lembrar Peter Wust (1884-1940) [...]; Romano Guardini (1885-1968) [...] e Max Müller (1906) [...]” (LIMA VAZ, Antropologia filosófica, v. 1, pp. 132-133).

${ }^{17}$ LIMA VAZ, Antropologia filosófica, v. 1, p. 132.

${ }_{18}$ Cf. ibid., p. 154.

${ }^{19}$ Ibid.

${ }^{20}$ PEGORARO, Ética e bioética, p. 94.
} 
Segundo o modelo contemporâneo da antropologia personalista, o único critério ético capaz de iluminar as discussões bioéticas em voga, e aqui especificamente o problema do aborto, é o critério do respeito absoluto à vida da pessoa. Porém, é necessário que esta vida seja compreendida na totalidade de suas dimensões estruturais, não levando em consideração apenas algumas dessas dimensões.

[...] A unidade da tríplice estrutura [somática, psíquica e espiritual] forma a identidade ontológica e permanente do ser humano que a antiga filosofia denominou substância. Esta identidade permanente é, ao mesmo tempo, impermanente, instável, evolutiva. Ou seja, o ser humano, sempre idêntico a si, é, ao mesmo tempo, um ser constituído por uma trama de relações instáveis ${ }^{21}$.

A vida humana é entendida, sob essa perspectiva, como tarefa a ser realizada pelo próprio sujeito. A existência do homem é dinâmica, não estagnada; é movimento, projeto, abertura ${ }^{22}$, caminho constante a percorrer rumo à vida. $\mathrm{O}$ homem, portanto, realiza-se no devir, por um movimento dialético de suprassunção das estruturas que o compõem. Ele se torna pessoa ao "fazer" a sua própria vida, ao assumir como própria essa vida que ele é, desde aquele primeiro instante em que surgiu como ser humano no ventre materno.

A pessoa humana é o único ser para o qual a vida é uma tarefa, porque ela não se reduz à dimensão de dado somático-psíquico. Sua existência está inacabada, não só do ponto de vista biológico, mas também espiritual e, principalmente, como unidade pessoal. A vida é, então, a história de uma contínua auto-expressão e, portanto, uma prolongada personalização. Assim, o sentido da vida está no próprio conquistar-se a si mesmo, como sujeito. A pessoa humana é protagonista da sua vida. [...] O valor da vida humana consiste em ser a base de suporte de uma existência pessoal, o lugar da liberdade que se plasma a si mesma, o pressuposto e o substrato de uma história irrepetível, a condição de possibilidade de relações intersubjetivas. Portanto, a vida é o bem básico e fundamental em relação a todos os outros bens e valores da pessoa humana ${ }^{23}$.

Reafirmando o núcleo ontológico do ser humano e introduzindo o conceito de pessoa como evento a ser realizado pelo próprio homem num processo de relações, "a ideia de um humanismo personalista é, portanto, a palavra final da Antropologia filosófica"24.

${ }^{21}$ Ibid., p. 96. O grifo é nosso.

${ }^{22}$ Cf. M. HEIDEGGER, Ser e tempo, 15ª ed., Petrópolis: Vozes, 2005, v. 1, pp. 184-194, 289-290.

${ }^{23}$ J.R. JUNGES, Bioética: Perspectivas e desafios, São Leopoldo: Unisinos, 1999, p. 116.

${ }^{24}$ LIMA VAZ, Antropologia filosófica, v. 1, p. 154. 


\section{A categoria de pessoa}

A categoria de pessoa é referência central em qualquer discussão ética. Somente quando se tem clareza do significado e da dignidade do outro enquanto ser pessoal, é que se pode vislumbrar um horizonte ético comum, a partir do qual a relação intersubjetiva se faz possível. Na reflexão filosófico-antropológica atual, o termo "pessoa" recebe várias e diferentes definições. A rigor, o conceito é bastante restrito, porém, faz-se urgente uma reflexão que amplie suficientemente a definição de pessoa, porque amplas e complexas são as questões bioéticas postas hoje, cujas respostas dependem fundamentalmente desta compreensão do caráter de pessoalidade.

É a mesma coisa dizer "vida humana" que "pessoa"? Em quê consiste ser uma pessoa? É alguém uma pessoa por ser racional, ou por ser capaz de tomar decisões livremente, ou por ser capaz de distinguir entre o bem e o mal (supondo que se saiba o que estes são), ou por ser capaz de dar-se conta de que pode sofrer e gozar, ou capaz de saber que morrerá inelutavelmente? Poderiam conceber-se pessoas que não fossem seres humanos, ou seres humanos que não fossem pessoas? [...] Quando começa a existir um ser humano, ou uma pessoa? [...] É uma pessoa, ou um ser humano, um "feto" "desde o primeiro momento", e quando começa este? Aos dois segundos, às duas horas, aos dois meses, aos seis meses? ${ }^{25}$

Geralmente, entende-se por pessoa um indivíduo que possui capacidade de raciocínio, interioridade, consciência de si e da realidade onde se encontra, autonomia, liberdade. "Alguns restringem o uso do termo pessoa àqueles indivíduos que já têm um claro desenvolvimento da capacidade de autoconsciência num grau menor ou maior"26. Dependendo dos critérios adotados a definição deste conceito pode apresentar-se, por vezes, arbitrária.

Os escravos, antigamente, não eram considerados como pessoas sob todos os pontos de vista; em algumas nações, mesmo nos dias de hoje, as mulheres não são, legalmente, consideradas pessoas com plenos direitos. Há algum critério objetivo para afirmar que o feto, o escravo ou a mulher não são pessoas no pleno sentido da palavra? O feto, obviamente, não é uma pessoa completamente desenvolvida. Quando um ser humano se torna uma pessoa? No ventre, no fim do segundo trimestre de gravidez ou na hora do

\footnotetext{
${ }^{25}$ J. FERRATER MORA / P. COHN, Ética aplicada del aborto a la violencia, Madrid: Alianza, 1983, p. 51. “¿Es lo mismo decir 'vida humana' que 'persona’? ¿En qué consiste ser una persona? Es alguien una persona por ser racional, o por ser capaz de tomar decisiones libremente, o por ser capaz de distinguir entre el bien y el mal (suponiendo que se sepa lo que éstos son), o por ser capaz de darse cuenta de que puede sufrir y gozar, o capaz de saber que morirá ineluctablemente? ¿Podrían concebirse personas que no fuesen seres humanos, o seres humanos que no fuesen personas? [...] ¿Cuándo empieza a existir un ser humano, o una persona? [...] ¿Es una persona, o un ser humano, un 'feto' ‘desde el primer momento', y cuándo empieza éste? ¿A los dos segundos, a las dos horas, a los dos meses, a los seis meses?" (ibid.).

${ }^{26}$ VARGA, Problemas de Bioética, p. 65.
} 
nascimento? Ou mesmo mais tarde, quando ingressa no primeiro grau de ensino e pode começar a ganhar a vida? Poder-se-iam arrolar várias condições arbitrárias e argumentar em favor da correção de cada uma delas [... $]^{27}$.

O conceito de pessoa pode ser tomado de forma bastante equívoca. Pode ser entendido, por exemplo, como o indivíduo necessariamente capaz de tomar consciência de tudo quanto está relacionado à sua interioridade e exterioridade; capaz de raciocinar, resolvendo problemas inéditos e complexos; capaz de tomar iniciativas de forma independente; e capaz de se comunicar sobre diversos temas e por diferentes meios. Se adotada esta concepção, então, como se deve "classificar" os seres humanos em situação de séria ou extrema debilidade por motivos físicos ou psíquicos ${ }^{28}$, $\operatorname{como}$ idosos, os portadores de necessidades especiais, os doentes mentais, os que sofrem doenças degenerativas, os que atravessam a fase final da vida, atormentados por doenças terminais, os que estão em estado de coma crônica? Também as crianças, nos primeiros meses e anos de seu desenvolvimento, parecem não se comportar de forma a corresponder às exigências de tal conceituação de pessoa. Então, o ser humano que se encontrasse em qualquer um dos casos exemplificados estaria excluído da comunidade moral por não atender às potencialidades acima postuladas numa suposta e restritiva definição de pessoa?

\section{Conforme Canto-Sperber,}

a maior parte dos autores que tratam da questão do aborto, fazendo do feto uma não-pessoa, atribui ao fato do nascimento uma importância decisiva [...]. À primeira vista, isso é estranho: por que o nascimento constituiria uma linha de demarcação especialmente importante? Não existem diferenças moralmente significativas entre um feto alguns instantes antes de vir ao mundo e um recém-nascido alguns instantes após seu nascimento. Raciocinar assim também parece ir diretamente contra o princípio de justiça: com efeito, um recém-nascido prematuro será, pelo simples fato de seu nascimento precoce, um membro integral da comunidade moral, titular do direito à vida. Em troca, um feto igualmente desenvolvido, mas ainda no útero materno, não será protegido contra um aborto tardio. Casos semelhantes não seriam, portanto, tratados de maneira semelhante ${ }^{29}$.

De fato, o embrião não pode ser considerado como pessoa no sentido pleno do conceito - provavelmente nenhum ser humano de carne e osso o possa - pois carece de certas qualidades pessoais que só poderão ser adquiridas ao longo do seu desenvolvimento até a idade adulta. Porém, o dia do nascimento não constitui, de forma alguma, um critério válido para se

\footnotetext{
27 Ibid.

${ }^{28}$ Cf. M. CANTO-SPERBER (org.), Dicionário de ética e filosofia moral, São Leopoldo: Unisinos, 2003, v. 1, p. 26.

${ }^{29}$ Ibid., p. 27.
} 
conferir o grau de pessoalidade. Também não podem ser denominadas "pessoas", a rigor, os bebês recém-nascidos e as crianças nas primeiras fases da infância ${ }^{30}$, antes de atingirem um certo grau de independência, consciência, individualidade e uso da razão. Todavia, sempre se incorre no risco de estipular arbitrariamente este suposto grau a partir do qual se passaria a ser, de fato, pessoa. E a história recente mostra que o homem moderno, autônomo e esclarecido, "iluminado" pela luz da razão, não está emancipado do risco de "enganar-se" na definição e aplicação de determinados conceitos vitais. De fato, nações inteiras deixaram-se mover e tomaram as armas pelo conceito doentio de "pessoa" definido por Adolf Hitler. Eram "pessoas" do século da tecnociência: 55 milhões de mortos, 35 milhões de feridos, 20 milhões de órfãos, 190 milhões de refugiados... Qual foi o conceito de "pessoa" empregado nos laboratórios nazistas? O que se entendia por "pessoa" em Auschwitz e nos outros campos? Qual a definição de "pessoa" aplicada em Hiroshima e Nagasaki?

Conforme R. Jungues, sob a perspectiva antropológica personalista

[...] pode-se dizer que o embrião, desde o primeiro momento, tem personeidade (estruturas antropológicas para tornar-se pessoa), mas ainda não pessoalidade (as estruturas ainda não foram levadas à expressão, enquanto sujeito). Em outras palavras, já é estruturalmente pessoa, embora não o seja atualizadamente, porque a estrutura pessoal ainda não se desenvolveu plenamente, mas está programada para isso. O desenrolar da estrutura humana será levado a cabo, se não for interrompido ${ }^{31}$.

O embrião, como pessoa em formação, participa daquele movimento dinâmico que constitui uma das características fundamentais de todo ser humano: o devir. Nessa perspectiva, o feto, da mesma forma que a criança já nascida, não adquire direitos pelo simples fato de nascer, mas pelo fato de ser humano ${ }^{32}$, pelo fato de pertencer à comunidade humana, ao gênero humano. Nesse sentido, "o professor de Ética médica J.-F. Malherbe defende a solidariedade ontológica como argumento que evita as controvérsias sobre a definição de pessoa"33. Ao embrião humano é devida, portanto, a "solidariedade ontológica" que diz respeito a todos os seres humanos. Nas palavras de Espinosa, "todos estamos ligados uns aos outros por natureza, e não por um simples contrato social livremente estabelecido pelas partes" ${ }^{\prime 3}$.

Para defender o respeito absoluto à vida humana já presente no zigoto, deve-se fazer uso, portanto, do argumento de "ascrição". To ascribe (atri-

\footnotetext{
${ }^{30}$ Cf. JUNGES, Bioética, p. 136.

31 Ibid., p. 137.

${ }^{32}$ Cf. J. NEDEL, Ética aplicada: Pontos e contrapontos, São Leopoldo: Unisinos, 2004, p. 22 .

33 JUNGES, Bioética, p. 139. O grifo é nosso.

${ }^{34}$ ESPINOSA, apud NEDEL, Ética aplicada, p. 22.
} 
buir) é o conceito usado por Paul Ricoeur e Lucien Sève ampliando o horizonte da reflexão bioética na definição do termo pessoa e da dignidade pessoal do feto humano ${ }^{35}$.

Conforme Lepargneur,

"pessoa", resumidamente, é o indivíduo consciente, dotado de corpo, razão e vontade, autônomo e responsável. Salientamos a autonomia da pessoa como sujeito moral, porque aqui enxerta-se toda a tradição kantiana, ainda hoje importante na dinâmica do desenvolvimento da conscientização dos direitos humanos. É óbvio que, nem o embrião, nem sequer o feto, nem o louco que perdeu, de vez, o uso da razão e juízo, nem o comatoso em fase final, respondem a esta definição da pessoa. Então, a pergunta é: em virtude de que podemos atribuir dignidade pessoal a estes seres [fetos, crianças, idosos, doentes mentais, portadores de necessidades especiais, pacientes terminais, comatosos] que não se enquadram na definição comum e admitida de pessoa? A resposta da ciência atual é pela "ascrição", isto é, pela atribuição de certa dignidade pessoal, outorgada criteriosamente, a seres que julgamos merecedores dela, pela proximidade que intuímos desfrutar conosco, apesar de eles não satisfazerem os critérios da definição clássica da pessoa, sujeito racional, livre, autônomo e responsável. A "ascrição" não resulta de uma decisão individual, mas de um juízo comunitário, cultural (do ethos), que admite mais ou menos, porque toda participação admite mais ou menos ${ }^{36}$.

A "solidariedade ontológica", à qual se refere Malherbe, é aquela atitude de consideração e respeito primordiais que se deve ter para com todo o semelhante. Trata-se da atitude de reconhecer o outro como semelhante, como participante da mesma espécie humana, do gênero humano, da mesma família. Nesse sentido, a vida intrauterina, desde o momento da concepção, por ser biologicamente humana, deve ser reconhecida como tal, e, por conseguinte, devem-lhe ser atribuídos a consideração, o respeito e o valor absoluto que concernem a toda e qualquer pessoa. "O ser humano é todo ser biológico pertencente à espécie humana [...]. A solidariedade ontológica dos seres humanos está baseada no fato de todos pertencerem ao mesmo filão" ${ }^{\prime 37}$.

Tendo presente a perspectiva da antropologia filosófica personalista sobre a categoria de "pessoa" na reflexão bioética atual, conclui-se, com Junges, que,

[...] no início, é difícil qualificar o embrião como pessoa porque faltam vários elementos fundamentais como a indivisibilidade, a consciência e a possibilidade de se comunicar. Mesmo assim, deve-se afirmar que este ser embrional, que se tornará pessoa num certo momento da gestação, impossível de de-

\footnotetext{
${ }^{35}$ Cf. JUNGES, Bioética, p. 138.

${ }^{36}$ H. LEPARGNEUR, Bioética, novo conceito: A caminho do consenso, São Paulo: Loyola / Cedas, 1996, p. 44.

37 JUNGES, Bioética, p. 139.
} 
finir, tem o direito a um respeito radical e sempre mais ativo e inventivo, respeito que começa com o direito de continuar vivendo ${ }^{38}$.

No humanismo personalista de Lima Vaz a categoria de "pessoa" designa o homem compreendido como um "ser-relacional". A pessoa é "[...] existência formada por uma rede de relações que começa no seio materno, se amplia na família, na cultura e na política, ao longo de toda existência. A pessoa vai se construindo num processo de relações" 39 , mas, a partir de uma estrutura fundamental, qual seja, somática, psíquica e espiritual, dada já desde o momento da fecundação, o primeiro instante da vida humana. Assim, a pessoa humana não é reduzida ao aspecto biológico - como pretenderiam alguns agonizantes paradigmas cientificistas e mecanicistas do nosso tempo - e nem fechada numa substância metafísica plenamente dada - o que constitui a acusação levantada contra os personalismos de inspiração cristã antes pelo contrário, trata-se de uma abertura imensurável ao novo, às experiências, à infinitude da vida, ao outro. O humanismo de Lima Vaz deixa claro que essa realização da pessoalidade só é possível pela via das relações. Somente nessa dinâmica inimaginável de abertura, de quem compreende-se um ser inacabado, um ser sedento de infinito, de transcendência, é que se dá a realização das possibilidades de ser pessoa, ou seja, a elevação do dado somático à expressão de sua humanidade. É no espaço histórico-temporal, onde se travam as relações humanas, que se definem a personalidade e a pessoalidade do ser humano. "Portanto, a pessoa humana é relação... a, abertura, convivência com os outros, com o mundo e com Deus" ${ }^{40}$.

Este é o sentido da pessoa. Longe de ser um indivíduo fechado sobre si mesmo e distante dos outros seres (este é o significado da palavra indivíduo), a pessoa é um ser-aberto ao mundo, não só porque é capaz de entendêlo, mas, também, porque é um ser carente, necessitado, incompleto que vai se completar na convivência com todos os outros seres [...]. Eis o que faz a dignidade humana. A pessoa é insubstituível porque é o único ser portador da inteligência e da liberdade, não para seu uso exclusivo, mas para servir a todas as outras criaturas. Insubstituível e sempre inegociável, por isso a pessoa é referência central da ética, princípio vivo da ética cósmica $[. . .]^{41}$.

Ao contrário do que afirmam alguns filósofos - talvez mais "atrasados" do que aqueles a quem acusam - a antropologia personalista não demonstra receio algum em perceber o ser humano como existência relacional aberta. É justamente numa dinâmica de relações, com o mundo, com os outros e com o Absoluto, que o ser humano vai, dialeticamente, elevando o dado biológico do seu existir à expressão propriamente humana da sua vida, o ser homem. Através desse movimento é que ele se torna pessoa, atualizando a sua

\footnotetext{
${ }^{38}$ Ibid., p. 140.

${ }^{39}$ PEGORARO, Ética e bioética, p. 63.

${ }^{40}$ Ibid., p. 55.

${ }^{41}$ Ibid., pp. 26-27.
} 
personeidade - as condições estruturais para torna-se pessoa - que já está presente, como fundamento e potencialidade, na forma mais inicial e frágil da vida: o zigoto. É inegável, portanto, o espaço fundamental da existência temporal da pessoa, que "[...] se constrói ao longo dos anos num processo de relações com os outros [...], explicitando, assim, suas potencialidades ${ }^{\prime \prime 2}$. $\mathrm{O}$ corpo físico-biológico e a temporalidade da existência constituem este espaço próprio da realização do "evento" que é a pessoa humana.

O humanismo personalista de Lima Vaz é também classificado como antropologia relacional, por entender a realização da pessoa humana somente a partir da categoria de relação ${ }^{43}$. Sob este paradigma antropológico, e sendo a bioética uma reflexão crítica acerca das relações humanas mediadas pela vida, sem uma visão unitária da pessoa, isto é, como ser portador de elementos próprios de estrutura e relação, e que realiza sua pessoalidade pelo intermédio e suprassunção destes elementos, "[...] não é possível resolver os conflitos entre direitos e deveres face à vida humana e a aplicação dos princípios bioéticos pode levar a [insuperáveis] impasses" ${ }^{\prime 4}$.

\section{O momento do tornar-se homem: da concepção até a morte}

Na imagem da criança, pretende-se que a humanidade seja honrada para além de toda utilidade, vantagens ou interesses. Neste sentido, a questão do aborto, sobretudo nos casos de gestação de criança portadora de patologias, torna-se a "prova real" de respeito para com todo o gênero huma${ }^{4}{ }^{45}$. Portanto, a pergunta referente ao aborto também pode ser feita da seguinte maneira: "A criança que não satisfaz a expectativa do adulto para a sua felicidade utilitarista, tem direito a viver e à existência humana?"46.

O recurso ao aborto não diz respeito a um problema unicamente socioeconômico, enfrentado por classes sociais economicamente desfavorecidas; trata-se, antes, de um "[...] fenômeno cultural, ligado ao modo de considerar a criança em função das necessidades e dos projetos próprios $^{\prime 47}$. Numa sociedade capitalista onde o imperativo utilitarista não se refere somente às coisas, mas também às pessoas, não surpreende a intenção de manipular a vida humana na sua forma mais indefesa, isto é,

\footnotetext{
${ }^{42}$ Ibid., p. 12.

${ }^{43}$ Cf. JUNGES, Bioética, p. 72 . O grifo é nosso.

${ }^{44}$ Ibid., pp. 72-73.

${ }^{45}$ Cf. B. HAERING, Medicina e manipulação: O problema moral da manipulação clínica, comportamental e genética, São Paulo: Paulinas, 1977, p. 115.

${ }^{46}$ Ibid.

${ }^{47}$ SPINSANTI, Ética biomédica, p. 66.
} 
no período da gestação. Para tanto, procura-se negar a identidade ou a pessoalidade do feto, definindo-o como "tecido" ou "matéria genética", considerando-o até como organismo intruso no corpo da mulher, do qual ela tem todo direito de se livrar ${ }^{48}$. Segundo Haering,

o aborto deixou de ser questão moral para os manipuladores e para os próabortistas que aceitam o cálculo utilitarista. [...] O movimento abortista é uma manifestação da sociedade de consumo, na qual a atividade sexual homossexual ou heterossexual - é considerada artigo de consumo que nada tem a ver com o amor, o empenho ou responsabilidade social. Quando uma sociedade julgar que a vida de um homem ainda não vindo à luz pode depender da vontade e, quiçá, do capricho de outrem, o comportamento das mães e dos pais e do mais vasto ambiente social mudará em relação ao feto, aos recém-nascidos e a todos nós ${ }^{49}$.

Filosoficamente, o ser humano deve ser sempre entendido, independentemente de sua forma, estágio ou situação, como pessoa humana, sujeito moral, e nunca uma coisa. Do contrário, incorre-se no risco de coisificar o ser humano, indo contra todos os princípios éticos que norteiam a reflexão antropológica contemporânea. Em face disto, na atitude de desprezo às vidas humanas fragilizadas reflete-se, não o avanço da civilização, nem o progresso das ciências, mas, muito pelo contrário, a decadência moral de uma sociedade que perdeu o rumo e o horizonte ético; que perdeu o sentido do próprio agir humano no mundo. "[...] Nossa história cultural mostra claramente a oposição constante entre processos de humanização e desumanização" ${ }^{50}$. O desprezo às vidas humanas fragilizadas, e, dentre elas, eminentemente a do embrião, reflete a atualidade da cultura dos mais fortes, daqueles que oprimiam e matavam todos quantos não atendiam às suas expectativas ${ }^{51}$.

"Antropologicamente, toda vida é convocada a desabrochar. Assim, retirar ou abreviar uma vida nascente é um ato contra a natureza em relação ao ser humano" ${ }^{52}$. Convém que as autoridades públicas, responsáveis pela promoção de políticas para o bem-estar da sociedade, persigam de forma coerente o ideal de oferecer melhores condições sociais, econômicas, psíquicas, e outras, aos "pequenos". Sabe-se que essa não é a atual realidade, então, as sociedades se utilizam do aborto como solução para o "problema" ${ }^{53}$. Num contexto social, como o atual, esfacelado moralmente, que atravessa uma crise profunda de valores, tendendo

[...] a ser orientado mais pela lei do que pela consciência, o povo é manipulado mais facilmente pelos gestores da opinião pública quando os intérpretes oficiais da lei declaram que toda mãe e todo médico, quando houver o

${ }^{48}$ Cf. HAERING, Medicina e manipulação, pp. 116-117.

${ }^{49}$ Ibid. O grifo é nosso.

${ }^{50}$ BOMBASSARO / PAVIANI, As fontes do humanismo latino, p. 28.

${ }^{51}$ Cf. <http://www.cnbb.org.br/2005/index.php>. Acessado em: 16 ago. 2005.

${ }^{52}$ PESSINI / BARCHIFONTAINE, Problemas atuais de bioética, p. 226.

${ }^{53}$ Cf. ibid. 
consentimento da interessada, pode impor a pena de morte à criança não nascida ${ }^{54}$.

A Assembleia Geral da Nações Unidas, através da Declaração dos direitos da criança (1959), afirma: “A criança [...] precisa de particular proteção e de cuidados especiais, inclusive de adequada proteção jurídica, tanto antes, como depois do nascimento" 55 . A Assembleia do Conselho da Europa aprovou uma resolução, em 1979, afirmando que tanto a ciência como o bom senso entendem que "[...] a vida humana inicia-se com o ato da concepção e, neste mesmo momento, estão presentes em potência todas as propriedades biológicas e genéticas do ser humano [... $]^{\prime \prime 56}$. A mesma resolução convoca os governos europeus que compõem o Conselho a adotar uma "[...] 'carta européia dos direitos da infância', a qual reconheça a cada criança 'o direito à vida desde o momento da concepção'" 57 .

A antropologia personalista responde aos grandes problemas éticos da atualidade oferecendo uma visão integral do homem, como ser de radical unidade, estruturado e relacional, e propõe uma nova interpretação da categoria de "pessoa". Filosoficamente, diz-se que as relações humanas encontram-se fundadas no aspecto do simbólico, isto é, no aspecto linguístico. O homem é um ser fundado na linguagem; é aquele que habita a casa da linguagem ${ }^{58}$. É ele o único ser capaz de interrogar-se pelo sentido das coisas, da realidade ao seu redor, do mundo, e de suas próprias ações. Ele é o único ser capaz de formular respostas às questões que lhe são colocadas; é o único que é convocado e se convoca pela palavra. O que diferencia o homem dos demais seres presentes no universo é justamente a sua capacidade de consciência, racionalidade, subjetividade, intersubjetividade, liberdade e espiritualidade. Com tais características, cabe a ele "humanizar" a sua própria existência, bem como tudo aquilo que cria ${ }^{59}$.

É isso que o personalismo afirma ao compreender a realização da pessoa como a elevação do dado à expressão, pela suprassunção das estruturas somática e psíquica, sempre num processo de relações, chegando à vida na dimensão do espírito. A expressão, de que se fala, é expressão da própria humanidade do indivíduo, da qual ele participa, por fazer parte do gênero humano, desde o momento de sua concepção. É a expressão daquela condição que lhe é intrínseca, a explicitação da humanidade implícita no homem desde seu primeiro instante de existência. Então, o sujeito, ao expressar-se como humano, humaniza-se a si mesmo, faz-se homem. Tal expressão constitui a tarefa primeira e última a ser realizada pelo indivíduo; é a dinâmica de sua vida: humanizar-se. O homem se torna homem.

\footnotetext{
${ }^{54}$ HAERING, Medicina e manipulação, p. 117.

${ }^{55}$ Cf. COMPAGNONI / PIANA / PRIVITERA, "Interrupção da gravidez", p. 642.

${ }^{56}$ Ibid.

${ }^{57}$ Ibid.

${ }^{58}$ Cf. HEIDEGGER, Ser e tempo, v. 1, pp. 218-226.

${ }^{59}$ Cf. PESSINI / BARCHIFONTAINE, Problemas atuais de bioética, p. 230.
} 
Na tentativa de responder à questão sobre o momento do início da vida humana, e de sua pessoalidade, a antropologia filosófica afirma que o homem não se torna homem no sentido de passar a ser humano, ou ficar humano, a partir de um momento determinado, calculado com a precisão científica de um cronômetro. Nesse sentido é que Blechschmidt afirma que "o homem não se torna um ser humano, é-o [...] em todas as fases do seu desenvolvimento, desde o momento da fecundação"60. A partir da concepção "não acontece nenhum fenômeno que torne humano o que (ou quem) já não o era. $\mathrm{Na}$ formação do ser humano há o desenvolvimento de potencialidades presentes desde o início" ${ }^{61}$. A expressão "tornar-se homem" deve ser entendida como o desenvolvimento dessas potencialidades próprias do ser humano, que acontece através da teia de relações que o sujeito tece ao longo de toda a vida. Por isso, a construção da pessoalidade é uma tarefa para toda a vida, porque o homem nunca é um ser acabado, pelo contrário, é alguém que está sempre fazendo e fazendo-se.

É certo também que o embrião não tem vida humana plena, mas é um fato inegável que é um vivente humano, porque a sua vida está programada para ser humana plena e desenvolver-se-á a partir das potencialidades intrínsecas sem nenhum salto qualitativo como vida humana ${ }^{62}$.

O tempo da vida de uma pessoa sempre foi e continua sendo contado pelo número de anos que ela vive. É interessante notar que em antigas tradições orientais, como na China e no Japão, antes acreditava-se que a criança recémnascida já contasse com um ano de idade ${ }^{63}$. Com o advento das ciências embrionárias, o espaço até então sagrado do útero materno foi penetrado e seus mistérios desvelados, possibilitando a análise de todo o crescimento e desenvolvimento do feto em gestação. Por fim, a psicologia contemporânea revela que no ventre materno já se estabelecem fundamentais "relações afetivas", não só biológicas, entre o embrião e a mãe. "Durante nove meses, o ser em gestação é modelado pelas trocas biológicas e relacionais que existem entre ele e a mãe $e^{\prime 64}$. Tais descobertas e teorias sobre o comportamento humano durante o período da vida intrauterina parecem nos reportar àquela visão das milenares tradições. "À vida de cada indivíduo são acrescentados os nove meses da gestação: segmento da vida a respeito do qual começamos a descobrir que tem papel determinante sobre o que vem depois" 65 .

O feto em gestação já é possuidor de identidade humana e pessoal, pois é o mesmo ser, e não outro, "[...] desde o óvulo fecundado até o nascimento e até a idade adulta. É diferente de qualquer outro ser. Parece que a vida humana

${ }^{60}$ FUNDAÇÃO SIM À VIDA, Mulher... por que choras?: O sofrimento das mulheres depois do aborto, São Paulo: Paulus, 2001, contracapa.

${ }^{61}$ NEDEL, Ética aplicada, p. 22.

62 JUNGES, Bioética, p. 137.

${ }^{63}$ Cf. SPINSANTI, Ética biomédica, p. 55.

${ }^{64}$ PESSINI / BARCHIFONTAINE, Problemas atuais de bioética, p. 229.

${ }^{65}$ SPINSANTI, Ética biomédica, p. 55. 
é um contínuo desenvolvimento e crescimento, desde a concepção até a morte $^{\prime \prime 66}$. Essa forma específica de ser humano, que transcende sobremaneira o mero dado físico-corporal, deve ser construída, cotidianamente, pelo sujeito ${ }^{67}$. O homem desde sempre é homem, e é, da mesma forma, desde sempre convocado a tornar-se homem, a expressar a sua humanidade.

\section{Segundo Bombassaro e Paviani,}

mais do que em qualquer outro momento da história humana, hoje sabemos que o que nos torna humanos é [também] nossa maneira de viver. [...] Tornamo-nos humanos na convivência. Podemos ser humanos, se escolhermos modos de ação que sejam adequados à nossa condição. [...] Nosso aparecimento no mundo não garante, por si só, que já sejamos plenamente humanos. Tornamo-nos humanos à medida em que, para além de nossa constituição biológica, crescemos numa determinada maneira de viver dentro de uma comunidade humana. É somente nessa interação que [...] constituímos e construímos um mundo propriamente humano ${ }^{68}$.

Faz-se necessário destacar, mais uma vez, que a expressão da humanidade do homem só é possível de ser realizada a partir das estruturas próprias que o constituem, estruturas da condição humana do indivíduo, que já estão dadas no momento da fecundação. A partir da concepção, a humanização do sujeito é um processo contínuo a ser desenvolvido por ele próprio, na dinâmica das relações fundamentais de objetividade, intersubjetividade e transcendência ${ }^{69}$. Destarte, num paralelo com o princípio da solidariedade ontológica, poder-se-ia fundamentar uma outra escola do início da vida, mencionada por Callahan. É a escola do vínculo, vínculo humano, escola das relações que definem o significado de uma vida humanizada ${ }^{70}$.

Hoje, graças ao desenvolvimento da autoconsciência, [...] conseguimos compreender melhor que a "essência" do ser humano se encontra na nossa existência, nesse tornar-se enquanto um processo dinâmico e permanente de autoconstituição do humano. Nesse sentido, nos compreendemos como humanos; somos humanos porque nascemos, crescemos, vivemos e morremos entre humanos $[\ldots]^{71}$.

Quando inicia a vida? Sob a perspectiva genética, a vida é transmitida, e nessa transmissão estão presentes as características de uma vida qualitativamente humana, desde a fecundação ${ }^{72}$. Conforme a tradição cristã, na concepção começa uma nova vida, dom do Criador e, ao mesmo tempo,

\footnotetext{
${ }^{66}$ VARGA, Problemas de Bioética, p. 69.

${ }^{67}$ Cf. BOMBASSARO / PAVIANI, As fontes do humanismo latino, p. 18.

${ }^{68}$ Ibid., p. 24.

${ }^{69}$ Cf. JUNGES, Bioética, pp. 86-96.

${ }^{70}$ Cf. PESSINI / BARCHIFONTAINE, Problemas atuais de bioética, p. 230.

${ }^{71}$ BOMBASSARO / PAVIANI, As fontes do humanismo latino, p. 18.

${ }^{72}$ Cf. PESSINI / BARCHIFONTAINE, Problemas atuais de bioética, p. 230.
} 
responsabilidade e tarefa a ser assumida pela pessoa. Em seu mistério, a vida do ser humano encerra um caráter de sacralidade e, portanto, é inviolável. No horizonte da antropologia filosófica, conforme o humanismo personalista defendido por Lima Vaz, o homem já é e torna-se homem, desde o primeiro até o último instante de sua vida. Nesse sentido, a vida humana começa na fecundação, mas não só aí, começa, também, no momento da convocação à palavra ${ }^{73}$; começa no momento em que se estabelece o relacionamento com o mundo, com o outro, e com o Absoluto; começa no momento do encontro com a razão, a consciência, a liberdade, o amor.

\section{Concluindo}

O presente texto procurou refletir sobre a pergunta pelo momento inicial da vida humana à luz de uma antropologia filosófica que apresenta o homem na radical unidade das categorias de estrutura e relação: o humanismo personalista de Lima Vaz. A antropologia filosófica personalista oferece uma visão integral do ser humano. Busca retomar a unidade do sujeito humano porque compreende o indivíduo como ser estruturado e relacional. Nesse sentido, a categoria de "pessoa" é indispensável para a discussão bioética. Ela constitui o critério ético fundamental, sem o qual não se pode desenvolver e orientar nenhum debate sobre os grandes desafios morais do homem, sobretudo o aborto.

É evidente que o feto não é uma "pessoa" no sentido estrito do conceito, porém, aplicando-se a ele os princípios do humanismo personalista de Lima Vaz, o zigoto é compreendido como ser já portador daquelas estruturas biológicas e antropológicas propriamente humanas, a partir das quais o sujeito é convocado a construir-se, tornar-se, realizar-se como pessoa, num processo dinâmico de relações com o mundo, os outros e o Absoluto. Desse modo, o feto possui, desde o momento da concepção, vida e personeidade humanas. Depois da fecundação do óvulo não há momento algum que se possa identificar como o marco inicial da vida humana no feto, ou que se possa definir como o instante em que se tornou pessoa. Insistir na pretensão de encontrar e "provar" a existência de tais momentos significa um verdadeiro absurdo filosófico e ético. A partir da concepção o que acontece é o desenvolvimento de potencialidades presentes no embrião desde seu primeiro instante. Os argumentos para defender o direito absoluto do feto à vida são, portanto, os de personeidade, ascrição e solidariedade ontológica.

O homem não se torna aquilo que já não o é. Ele se torna pessoa à medida que vai expressando a própria humanidade; realiza-se enquanto desenvolve o processo de elevação do dado à expressão. O homem já é e torna-se

${ }^{73}$ Cf. ibid. 
homem. Sua tarefa é realizar-se como pessoa humana ao longo de toda a vida. Da concepção até a morte é que o homem torna-se homem. Da concepção até a morte é que o ser humano torna-se pessoa. O momento de tornar-se homem e pessoa é um só, exato e preciso: o momento da vida.

Obedecendo à formulação do imperativo categórico kantiano que declara o homem como fim em si mesmo, o aborto não pode ser usado como meio para resolver situações conflitivas que digam respeito à gestação ou à gestante, sejam de quaisquer ordens - terapêutica, emocional, psicológica, econômica, social ou moral - porque o que está em jogo é uma vida humana, constituída de valor absoluto.

O discurso pela defesa e legalização do aborto revela a incapacidade de se tocar nas grandes feridas sociais. A prática abortiva não pode ser considerada e legitimada como um direito da mulher, pois não se pode conceber como um direito a ação de matar um inocente. O aborto não é "solução" para nenhum problema social, constitui tão somente uma ação "paliativa". Compromisso coerente é o da luta pela defesa da vida e dignidade de todas as pessoas, especialmente dos mais "fracos", sejam fetos, crianças, jovens, idosos, portadores de necessidades especiais, doentes. Há que se combater as estruturas sociais causadoras do aborto, e não acolhê-lo como "solução" para tais questões. A prioridade deve ser a luta não pela dignidade do aborto, mas pela dignidade da vida da pessoa humana, independentemente do estágio ou situação em que ela se encontre.

O humanismo personalista de Lima Vaz constitui, portanto, um paradigma de fundamental referência para a reflexão filosófica acerca das grandes questões bioéticas dos nossos dias, especialmente o fenômeno do aborto, confrontando-o com os problemas do momento inicial da vida humana e do caráter de pessoalidade do embrião. A escolha pela visão de homem sob a perspectiva antropológica personalista de nosso autor significa uma opção ética.

Se a vida humana for compreendida como sagrada, portadora de um intrínseco valor absoluto, portanto inviolável, e se o embrião for entendido como portador desta vida qualitativamente humana e das capacidades estruturais próprias para realizar-se como pessoa, então, o abortamento, sob uma análise ética, assume o caráter de um dos mais cruéis e terríveis homicídios que se possa pretender contra um ser humano, na sua condição real mais frágil e indefesa.

Eleandro Teles, diácono da Diocese de Caxias do Sul, é bacharel em filosofia pela Universidade de Caxias do Sul (UCS) (Caxias do Sul, 2005) e bacharel em teologia pela Pontifícia Universidade Católica do Rio Grande do Sul (PUCRS) (Porto Alegre, 2009).

Endereço: Avenida França, 730 - Bela Vista 95076-000 Caxias do Sul - RS

e-mail: eleandrortm@yahoo.com.br 